\title{
THE NEW BOTANICAL LABORATORIES AT LIVERPOOL.
}

A $\mathrm{S}$ already announced, the new botanical laboratories, presented to University College, Liverpool, by $\mathrm{Mr}$. W. P. Hartley, of Aintree, were formally opened on Saturday, May Io, by Sir William Thiselton-Dyer, K.C.M.G., F.R.S., Director of the Royal Botanic Gardens, Kew. The laboratories, of which a sketch elevation has already appeared in NATURE (vol. lxi. p. 454, March 5, 1900), vie, both in size and equipment, with those of the University of Glasgow, opened last year by Sir Joseph Hooker.

The building, which is plain and unpretentious externally, covers an area of 3000 square feet, and con-

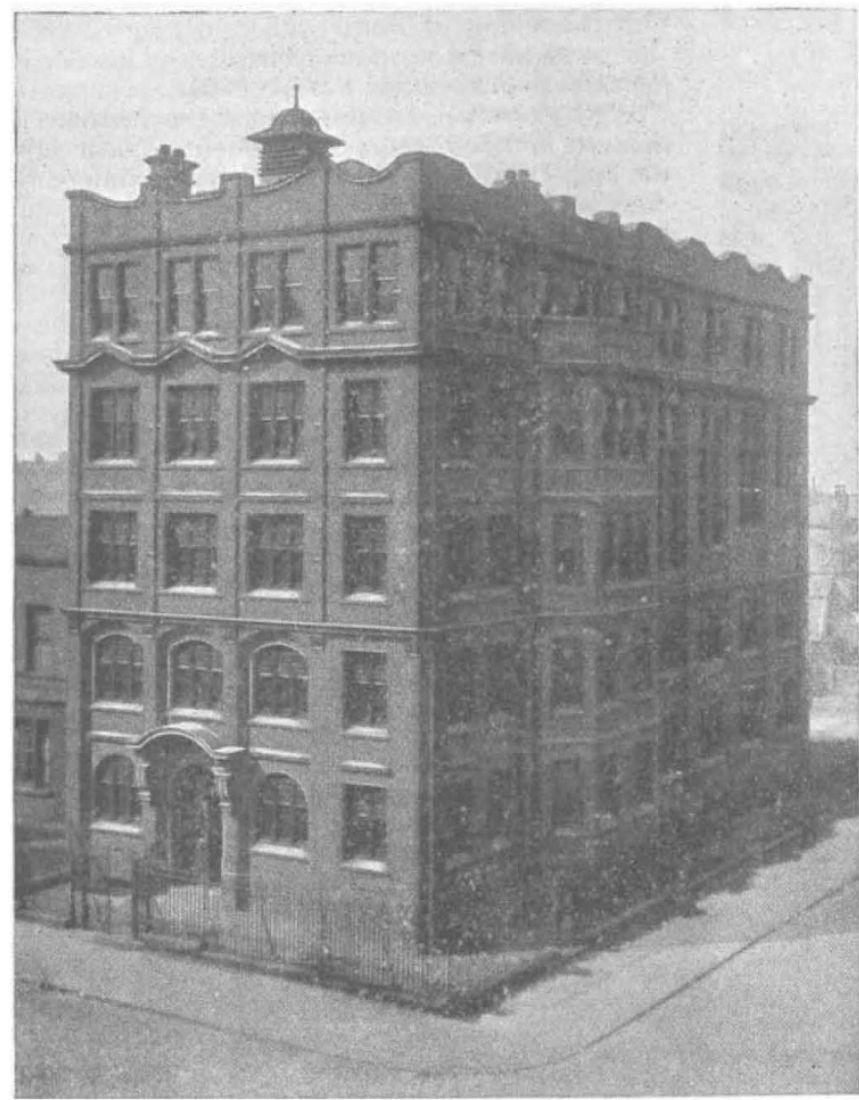

FıG. 1.-Hartley Botanical Laboratories, Liverpool.

research laboratories and dark room, whilst the second floor is occupied by the elementary laboratory, with accommodation for sixty-five students, the advanced laboratory, arranged to seat twenty students, and the assistant lecturer's private room.

The laboratories, museum and lecture rooms are fitted with pitch-pine and teak fixtures, and the building is lit throughout by electric light. All the laboratories, both public and private, are equipped with gas and water fittings, and baywood wall cases are provided for storage of apparatus and materials. The total cost of the building has been somewhat more than 13,000 ., including the cost of the freehold and $750 \mathrm{o}$. expended on museum glass and essential physiological apparatus.

The opening ceremony took place in the arts theatre of the College, where a large audience was presided over by Mr. E. K. Muspratt, vicepresident of the College, in the unavoidable absence of the president, Lord Derby. Amongst other botanists present were Sir William Thiselton-Dyer, Profs. Marshall Ward, Bretland Farmer, Weiss, Potter, Bottomley and Smith, and Mr. Wager. Sir Michael Foster, who expected to be present, was detained at the last moment by parliamentary business. Among the general guests were Sir John Brunner, M.P., Sir John Willox, M.P., Prof. Miller Thompson, Prof. Lord, \&c. The principal was accompanied by a large number of the College staff.

Mr. W. P. Hartley, in formally presenting the laboratories to the College, said that the citizens of Liverpool desired their city to be foremost, not only in commerce, but in knowledge, in the discovery of truth and the encouragement of science in its pure as well as in its applied branches. His object in providing the laboratories to the College was to help in the realisation of that ideal.

After the formal acceptance of the munificent gift by the chairman and the principal of the College (Prof. Dale), a vote of thanks to the donor was carried by acclamation and responded to in suitable terns by Mr. Hartley.

Sir William Thiselton-1)yer then delivered an address on the value of the study of botany as a means of cultivating the powers of observation and deduction from observed facts. He said his feeling in coming to the north from the metropolis was one of envy. $\mathrm{He}$ found a great commercial city full of busy life, possessing buildings and equipment for the pursuit of knowledge marked by a sumptuousness and magnificence the like of which was not possessed by them in London, and which they had little hope of obtaining. That grand municipal spirit existing among Liverpool citizens showed a height of local

sists of three main floors, accommodating the museum, lecture theatre and elementary laboratory behind, whilst by the interpolation of two mezzanines facing the main thoroughfare, space is found for private rooms, research laboratories, herbarium, class room and workshops. All the rooms open off a central staircase, lit from a lantern in the roof, thereby avoiding waste of space in the provision of corridors. A basement contains the storerooms, lavatories and heating chamber; the ground floor is occupied by the museum, museum preparation room and workshop. The first mezzanine carries the herbarium and class room, with an entrance to the gallery of the museum. On the first fioor is placed the theatre, seated for two hundred students, the professor's private room with a private laboratory adjacent, and the departmental library. On the second mezzanine are placed the NO. ITO2, VOL. 66] patriotism to which they had not attained in the metropolis. It was a lasting glory to her that Liverpool had undertaken so great a work, and he could not doubt that a blessing would come upon her citizens in the stimulus to that higher life the seeds of which they had planted.

The new laboratories, as the generous donor had said, were not intended to teach merely that which would lead to direct profit, they were intended also, and primarily, as a centre for the prosecution of research and study not necessarily utilitarian in its aim. The study of botany was calculated to foster to the highest degree the faculties of observation and deduction. Bluntness of observation was a national calamity, for the inability to see a thing at the moment it presented itself might mean the loss of a unique opportunity. Not in botany alone, but in all 
studies and occupations, the secing eye was of infiniteeven fundamental-cervice.

After a brief résumi of the history of botany in England and an appreciation of the services rendered to the science by men like ( $i t e w$, John Ray, Robert Brown and others, Sir IVilliam expressed the hope and belief that England would again attain and retain the premier place in botanical study and research, and that the botanists of Liverpool would sn use their splendid opportunities as to maintain the reputation of their country. He went on to speak of the great industries which had their origin in bofanical discoveries, of the value of the science to medicine, and pointed out a fact too often overlooked that plants were intimately connected with every phase and stage of human life until, in the final act of the drama, they facilitated our decay.

After a vote of thanks to Sir WVilliam Thiselton-I)yer for his address, proposed by Sir John Brunner, M.P., and seconded by Prof. Harvey Gibson, and the pre. sentation of memorial keys to Mr. Hartley and Sir

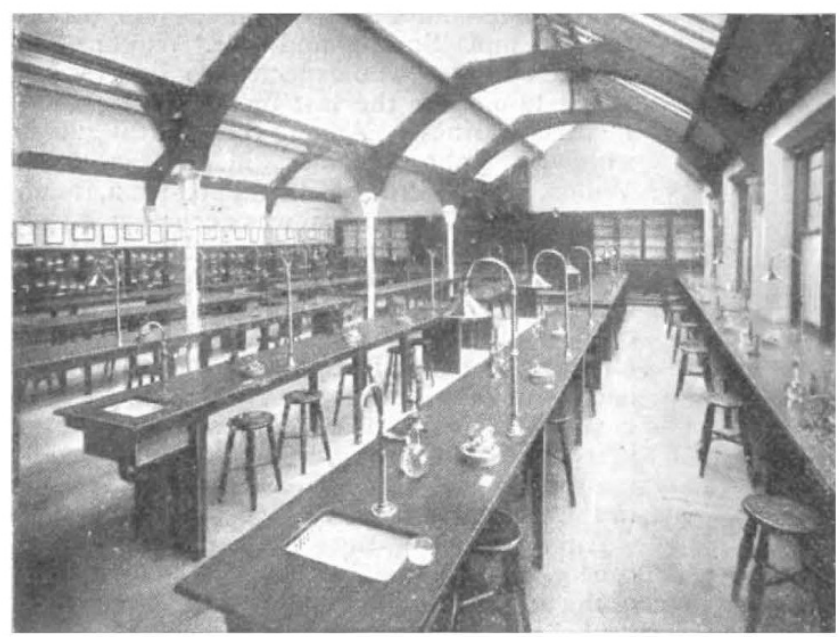

Fici. s--Elementary Laboratory. Hartley Latboratories, Liverpool.

William Thiselton-Dyer, the guests adjourned to the Hartley Laboratories, which were thrown open for inspection.

\section{THE HUGH WIILIER CENTENARI'}

THE proposal to celebrate the centenary of the birth of Hugh Miller during the present year has met with general approval, and the erection of an institute bearing his name in Cromarty has been admitted to be the best means of appropriately celebrating his memory.

It is intended that the Hugh Miller Institute shall take the form of a museum, where any relics pertaining to Miller can be kept; and a free library and reading room.

The centenary committee have had the promise of support from Hugh Miller's admirers in America and the colonies, as well as at home, and Mr. Carnegie, the generous supporter of such institutions as the proposed institute, has made the handsome offer to give $100 l$. for every $100 l$. raised by the committee.

It is desirable that the memorial should be as widely representative as possible, and the committee therefore appeal to all who appreciate the work accomplished by Hugh Miller in science and literature for contributions, in order that the scheme may be sufficiently advanced by the aniversary of his birth in October.

Contributions should be sent to the Treasurer, Commercial Bank, Cromarty.

No. I 702, voL. 66]
The movement has the support of the following :-

Lord Balfour of Burleigh, Secretary for Scrland: Sir Archibald (icikie, F.li:S., LL.T).; Prof. Masenn, L.L.D. Sir John I.eng. M.l': S Sir Walter Foster, M.P. ; C. J. Guthrie. K.C., Sheriff of Ross and Cromarty; iv. C. Smith, I.L. B. ; Prof. Duns, Edinburgh ; $A$. Taylor Innes, Esq., Edinhurgh ; l'rof. Clarke, State College, New Virk; W. Robertson Nicnl, LL. U. : A. Bignold, Esq., M.I', ; P'rincipal Rainy. D. D. ; Alexander Whyte. ID.D.; Colonel Ross. C B., of Cromarty: Mr. James Barron, Inzerners Courier; W. J. Watson, B.A., Secretarv Inverness Field Clul,.

$$
\text { I. Bain, Hon. Séc., }
$$

Cromarty, May, Igoz.

$$
\text { IJugh Miller Centenary Committee. }
$$

\section{LAZARUS FUCHS.}

THE name of Lazarus Fuchs will always be associated with the theory of linear differential equations, to which he gave an extraordinary impulse by his famous memoir published in the sixty-sixth volume of Crelle's Journal. In this paper the methods of modern function-theory are brought to bear upon the long-familiar process of solving a differential equation by scries. The coefficients of the equation being supposed to be uniform analytical functions with isolated singularities, it is shown how to obtain, in the neighbourhood of an ordinary point, a complete set of independent integrals ; the analytical form of these solutions is determined, and shown to depend upon a certain fundamental or indicial equation. It is proved, also, that the singularities of the integrals may be deduced from the coefficients without integration, and the notion of regular integrals is developed. The distinction is made between the integrals which involve logarithms and those which do not, and attention is drawn to those equations the integrals of which have no essential singularity. Thus in a single memoir of moderate length all the essential features of an extensive theory are presented in a clear and comprehensive outline.

In the rapid development which followed the publication of this memoir, the author naturally took a prominent part. Among his important contributions may be mentioned his researches on linear equations with algebraic integrals, on constructing linear equations the integrals of which have assigned singularities, and on equations the integrals of which are connected by algebraic relations. An instructive illustration of the general theory is given by his memoir on the equation satisfied by the elliptic integrals $K, K^{\prime}$.

When the independent variable describes a closed curve, a set of integrals undergo a linear substitution, and all the substitutions arising from different paths form a group associated with the equation. M. Poincare assigned the name of Fuchsian functions to functions invariant for a group of linear transformations of the variable in recognition of Fuchs's results concerning equations of the second order.

Fuchs's mathematical papers are very pleasant to read and free from that tendency to heaviness which is apt to belong to memoirs on differential equations. He had the faculty of bringing out clearly the really important points without over-elaborate detail, and he did not disdain to show the power of his methods by applying them to specific and definite problems. In these respects he may be compared with Halphen. While admitting that his way was prepared by the work of Cauchy, Briot and Bouquet, and Riemann, we may fairly claim for him that he has been the effective pioneer in a vast and fascinating region.

It is interesting to remember that Henry Smith, in a presidential address to the London Mathematical Society 